\title{
New Silvicultural Treatments for Conifer Peri-Urban Forests Having Broadleaves in the Understory - The First Application in the Peri-Urban of Xanthi in Northeastern Greece
}

\author{
Elias Milios ${ }^{1 *}$, Kyriaki Kitikidou ${ }^{1}$, Kalliopi Radoglou ${ }^{1}$
}

(1) Democritus University of Thrace, Department of Forestry and Management of the Environment and Natural Resources, Pantazidou 193, GR-68200 Orestiada, Greece

*Correspondence: e-mail: emilios@fmenr.duth.gr
Citation: MILIOS E, KITIKIDOU K, RADOGLOU K 2019 New Silvicultural Treatments for Conifer Peri-Urban Forests Having Broadleaves in the Understory The First Application in the Peri-Urban of Xanthi in Northeastern Greece. South-east Eur for 10 (2): 107-116. DOI: https://doi. org/10.15177/seefor.19-16

Received: 15 Jun 2019; Revised: 28 Aug 2019; Accepted: 11 Sep 2019; Published online: 31 Oct 2019

\begin{abstract}
Background and Purpose: In Greece, forest practice did not develop special silvicultural treatments for planted conifer peri-urban forests where broadleaf trees appear as natural regeneration in the understory. The aims of this study are: a) to analyze the new proposed selective silvicultural treatments for the planted peri-urban forest of Xanthi and for analogous planted conifer forests, where broadleaf trees are naturally established in the understory b) to check the research hypothesis that the new selective silvicultural treatments exhibited higher intensity in terms of the basal area of cut trees, compared to that of traditional treatments in the studied peri-urban forest.

Materials and Methods: In the traditional treatments, in the pine overstory cuttings, apart from the dead trees, mainly the malformed, damaged, suppressed and intermediate trees were cut. In the lower stories, the goal of the thinning was the more or less uniform distribution of broadleaf trees. In the proposed selective treatments, the main aim of pine cuttings is to release the broadleaf formations growing in the lower stories, while the treatments of the broadleaf trees will be a form of "positive selection" thinning. Plots were established in areas where the two types of treatments were going to be applied. In each plot, tree measurements and a classification of living trees into crown classes took place. After the application of the treatments the characteristics of cut trees were recorded.

Results: In the established plots, before the cuttings (and thinning), total basal area was not statistically significantly different between the two types of treatments. In selective treatments, the basal area of all cut trees was statistically significantly higher than that of the results of traditional treatments. In the broadleaf cut trees there were statistical differences in the ratios of dominant, intermediate and suppressed trees between the two silvicultural approaches.

Conclusions: The research hypothesis was verified. The intensity of treatments in terms of the basal area of cut trees was higher in the selective approach, compared to the traditional treatments in the Xanthi peri-urban forest. However, the overstory cutting intensity of the selective treatments depends on the spatial distributions and densities of broadleaved and conifer trees. In the broadleaf trees, the different objectives of the two types of treatments resulted in thinning with different qualitative characteristics. The proposed silvicultural treatments will accelerate the conversion of peri-urban conifer forests having an understory of broadleaf trees into broadleaved forests, or into mixed forests of conifers and broadleaf trees.
\end{abstract}

Keywords: peri-urban forests, silvicultural treatments, conversion, positive selection 


\section{INTRODUCTION}

In the peri-urban forests of Greece, conifers were artificially established in very dense spacings $(1 \times 1 \mathrm{~m})$ for the protection of forest soils in areas around cities and towns, as well as for the protection of the health and property of urban settlement residents [1].

In the north of Greece, within many peri-urban forests broadleaf trees were gradually established as natural regeneration under the canopy of conifers. This process resulted in formations where conifers (mainly pines) form the overstory, while broadleaf trees appear in the understory (and in some cases in the middlestory). As the planted conifer trees became older, exhibiting larger dimensions, and the density of broadleaf trees increased as a result of a continuous establishment, the competition among trees increased. Moreover, the available organic fuels became gradually higher, leading to a higher risk of wildfire. A wildfire in a peri-urban forest can have catastrophic results in many aspects. Apart from the destruction of the periurban forest, urban infrastructures may be destroyed. The most significant issue is that such fires may have huge costs in human lives (like in Attica in 2018). At the present, the component of broadleaf trees exhibits various densities, ages, dimensions and species compositions.

Another concern that the Forest practice has to incorporate in its design is their usage for recreation, regarding the manipulation-treatment of stand structure of peri-urban forests.

Areas with broadleaf trees are less vulnerable to forest fires, and broadleaf trees can react through sprouting against disturbances, such as wildfires or anything that can kill the aboveground part of trees [2-5]. As a result, the fast conversion of pine reforestations into broadleaved forest or to mixed conifer-broadleaf forest will contribute greatly to the reduction of forest fire risk, and also to the improvement of ecosystem resilience. A forest fire event can release a great amount of $\mathrm{CO}_{2}$ in the atmosphere, depending on the volume of the burned organic matter. That conversion will contribute to the reduction of the $\mathrm{CO}_{2}$ release risk and thus, it will act against the climate change process. Moreover, the ability of broadleaf trees to resprout after a forest fire will reduce - eliminate the costs of the vegetation re-establishment after the fire. Sprouts and sprouting ability can be used for the preservation of forest ecosystems during climate change period [6-8].

In Greece, forest practice did not develop special silvicultural treatments for planted conifer peri-urban forests in general, and in particular in peri-urban forests, where broadleaf trees appear as natural regeneration in the understory. The up to now applied silvicultural treatments are usually characterized by light intensity, while there are cases with medium to high intensity treatments. The cutting of dead trees and pruning are the common characteristics of treatments in peri-urban forests.

In the context of The FoResMit Project (LIFE14 CCM/ IT/905 "Recovery of degraded coniferous Forests for environmental sustainability Restoration and climate change Mitigation"), new selective silvicultural treatments were developed in Monte Morello peri-urban forest in
Italy and in the peri-urban forest of Xanthi in Greece and were applied together with the traditional silvicultural approaches $[9,10]$. In Xanthi, the proposed silvicultural treatments target in the fast conversion of the peri-urban forest in a broadleaf forest or in a mixed conifer-broadleaf forest, and thus are expected to exhibit high intensity.

The aims of this study are: a) to analyze the new proposed selective silvicultural treatments for the planted peri-urban forest of Xanthi, and for analogous planted conifer forests, where broadleaf trees are naturally established in the understory and b) to check the research hypothesis that the new selective silvicultural treatments exhibited higher intensity in terms of the basal area of cut trees compared to that of traditional treatments in the peri-urban forest of Xanthi. Moreover, the characteristics of the first application of selective treatments in comparison to those of the traditional treatments, are given and discussed.

\section{MATERIALS AND METHODS}

\section{Study Area}

The peri-urban forest of Xanthi $\left(41^{\circ} 09^{\prime} 27.3^{\prime \prime} \mathrm{N}\right.$, $24^{\circ} 54^{\prime} 09.8^{\prime \prime} \mathrm{E}$ ) is located on the slopes around the town of Xanthi in northeastern Greece. It covers an area of about $2400 \mathrm{ha}$, in an elevation range of 100 to $630 \mathrm{~m}$. In the periurban forest there are reforestations - plantations that began in 1936 and lasted up to 2007. However, most of them were established before 1973 [9, 10]. The reforestations cover a great part of the peri-urban forest. They were established mainly in degraded areas which were under grazing pressure. In those areas bare land alternated by areas of very sparse vegetation consisted of Carpinus orientalis L., Quercus coccifera L., Fraxinus ornus L., Quercus frainetto Ten., Quercus pubescens Willd., Quercus petraea Liebl. subsp. polycarpa (Schur) Soo etc. plants. In some cases, reforestations were established in agricultural lands with very small areas. The main species used in the reforestations was Pinus brutia Ten. [11], while some other species were also used. The main of them were Pinus maritima Mill., Robinia pseudoacacia L., Cupressus sempervirens L., and Pinus nigra J.F. Arnold. In the lower stories (mainly understory) there are naturally established broadleaved species like Carpinus orientalis, Quercus coccifera, Fraxinus ornus, Quercus frainetto, Quercus pubescens, Quercus petraea etc. In very few cases the tallest broadleaved trees had analogous height of their adjacent pine trees that were usually intermediate or codominant trees. In some areas, individuals of Robinia pseudoacacia L. have been naturally established under the pine overstory.

The deadwood in the reforestations of the peri-urban forest of Xanthi is $9.21 \mathrm{~m}^{3} \cdot \mathrm{ha}^{-1}$ [12].

The mean annual precipitation in the area of Xanthi is $675 \mathrm{~mm}$ while the mean annual temperature is $15.5^{\circ} \mathrm{C}$ [13]. In the areas where the treatments that are analyzed in this study were applied, the soil texture is sandy clay to sandy clay loam [10]. The treatments were applied in a part of reforestations that was established (mainly) in the decade of 1950 (Figure 1). 


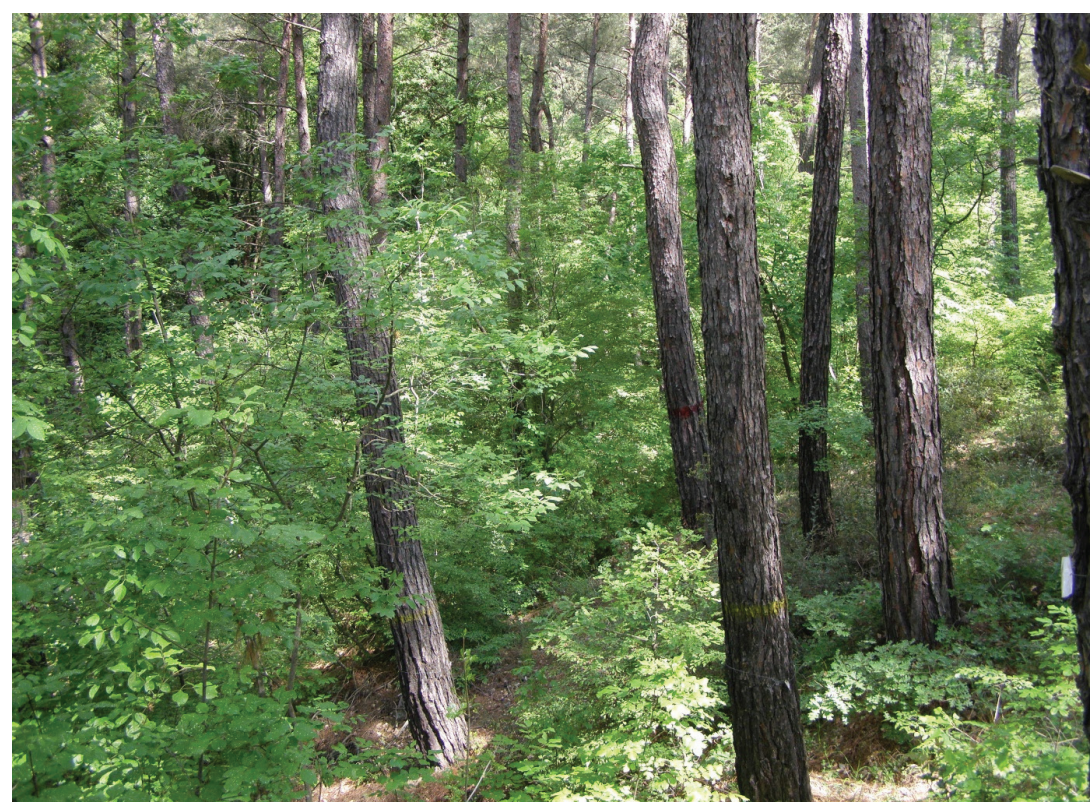

FIGURE 1. Reforestations of Xanthi peri-urban forest where broadleaf trees were established as natural regeneration.

\section{Silvicultural Treatments in the Peri-Urban Forest in Xanthi \\ Traditional Treatments}

In Xanthi, in the overstory cuttings of the traditional treatments (Figure 2), apart from the dead, mainly the badly formed, damaged, suppressed and intermediate trees were cut. The first priority was the cutting of the badly formed and damaged trees. The intensity of the cuttings depended mainly on the density of the conifer overstory, and usually it was light.
However, in some cases, in areas with rather dense overstory, where there were many badly formed trees, the intensity of the cuttings was much higher. In the lower stories, the goal of the thinning was the more or less uniform (if possible) distribution of broadleaf trees. In most cases, in the broadleaf tree thinning, the robust trees, as well as the trees with good form, were not cut. On the other hand, mainly trees with lower competitive abilities were removed. The intensity of the thinning in the lower stories was, almost in all cases, low.

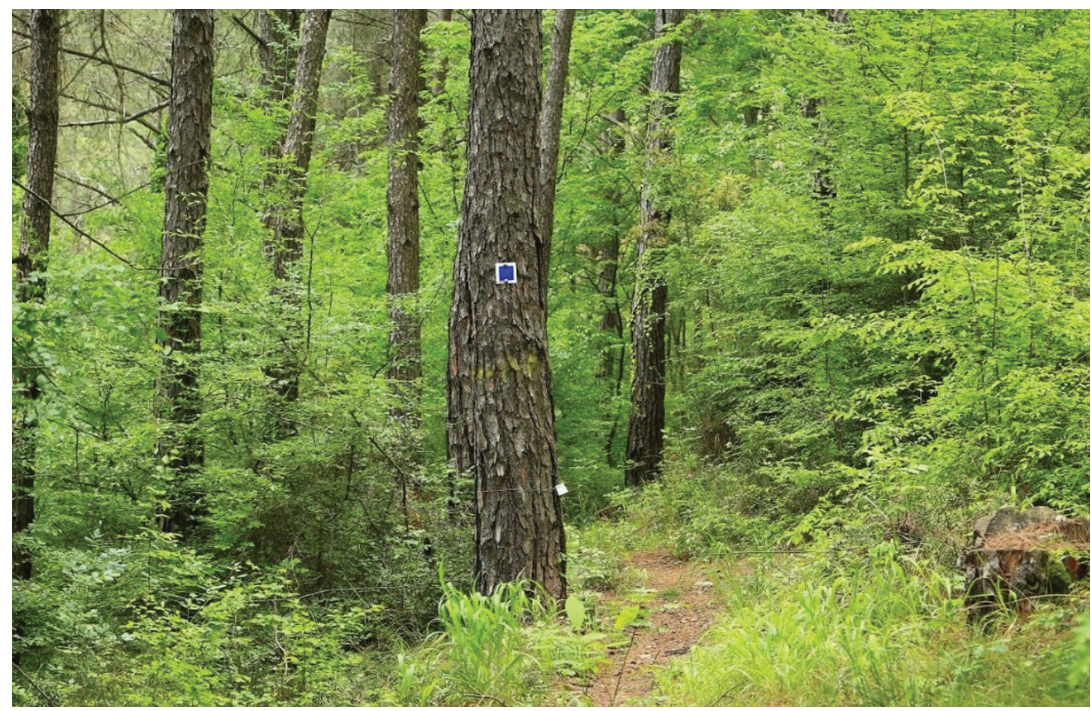

FIGURE 2. Area where traditional treatments were applied. 


\section{Selective Treatments}

In the following text Dafis [14], Oliver and Larson [15] and Smith et al. [16] were used as a theoretical base in order to develop the new proposed silvicultural treatments.

The so-called selective treatments include rather intense cuttings in the overstory of pines (conifers) and thinning in the broadleaf component of the lower stories.

The objective of the selective treatments is the fast conversion of the peri-urban forest in a forest where broadleaf trees will be the dominant element, and in later time in a broadleaved forest (at least in the better sites). Only in the worst sites Pinus brutia (conifers) will be the dominant component of the stands, since the most broadleaf trees are more site sensitive than pines [17-19].

The main aim of the overstory cuttings is the release of the broadleaf formations (thickets or groups) growing under pines (Figure 3). In the overstory cuttings, except for the dead, the badly formed and damaged trees will be cut. The first priority is the removal of the trees having large dimensions and bad form (if there is a sufficient ground cover by broadleaf trees or their regeneration). The trees having the best form will be retained. Those pines are expected to exhibit high growth rates. The intensity of the overstory cuttings will be higher in areas with dense (or rather dense) formations of broadleaf trees, or where there is rich regeneration of broadleaf trees. In this context, if after the removal of the badly formed and damaged trees, a tree (or trees) with rather good or even best form must be cut, in order for a broadleaf formation to be sufficiently released, then that tree (or those trees) has to be cut. As mentioned above, the main target, which must determine and guide the scheme of cuttings, is the release of the broadleaf component of the stand. In areas totally covered by dense or rather dense formations of broadleaf trees, all the overstory pines have to be removed, if possible, in one cutting application, if it is ensured that there will be no serious damages in the broadleaf stories.

The proposed selective silvicultural treatments will be applicable in peri-urban forest(s) having various spatial distributions and densities of broadleaved and conifer trees resulting in different needs of overstory cutting intensities.

Generally, the intensity of the pine overstory cuttings will vary depending on the density of the overstory trees, as well as on the density of the broadleaf trees of the lower stories (and in the regeneration level) and the necessity for their release.

In the new proposed selective silvicultural treatments, the thinning of the broadleaf trees will be a form of "positive selection" thinning. In the thinning, the main competitors of the selected best broadleaved trees will be cut. In each thinning application, in almost all cases, one (the primary) competitor of each selected to be favored tree must be cut [14]. As the best trees will be considered the trees (or saplings) having strong growth vigor, symmetric and large or rather large crown and, if it is possible, a good (straight, having circular cross section, without deficiencies) bole form. An essential feature, that all the selected best trees that are going to be favored must have, is a vertical stance. The thinning will provide more growing space to the most dynamic and promising broadleaved trees. The individuals that are going to be favored through that "positive selection" thinning must be distributed in the total stand area, if it is possible, since they are going to be the robust dominant having large dimensions trees that will give strength and stability in the stand in the future. In the locations where there are no broadleaf trees with the aforementioned desirable features, the comparatively (to the adjacent) better trees will be favored [14]. In areas where the best trees do not confront rather significant competition, no trees will be cut.

The production of quality wood must be considered as a secondary service in a peri-urban forest [1]. That is why, even though the good bole form is considered as a feature of the best trees, it is not a necessary one. The "positive selection" thinning of the broadleaf trees has to start when the best trees with the aforementioned features are easily identified.

In the broadleaf component when there are groups of sprouts, these must be gradually thinned so as the best sprouts, having a vertical stance, finally remain. In this gradual thinning, at first the sprouts having the worst form will be cut.

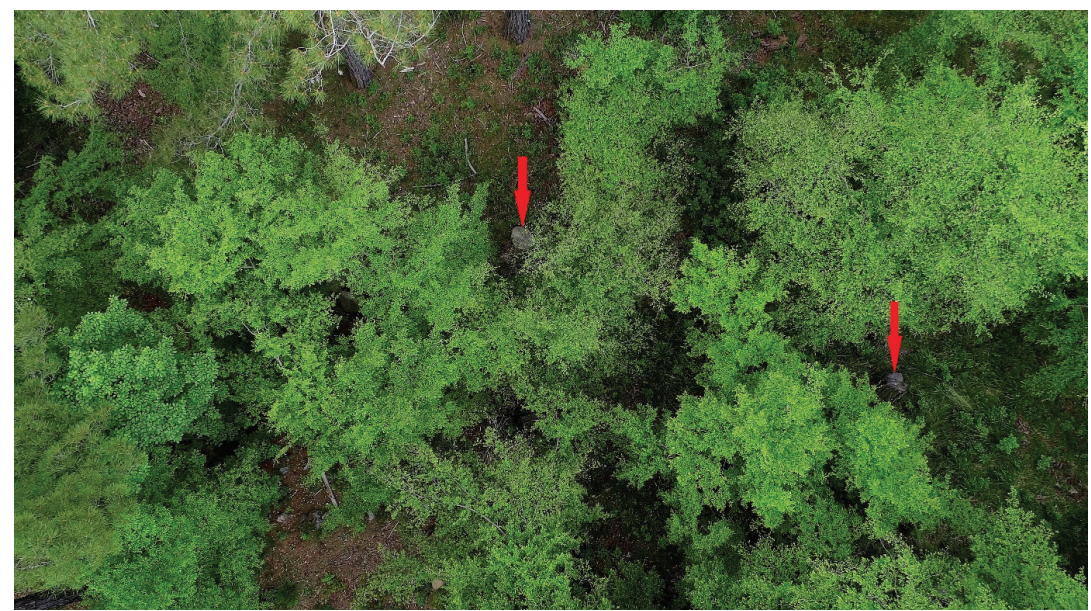

FIGURE 3. Broadleaf trees that were released from conifer competition in the context of selective silvicultural treatments (arrows aim at the stumps of the cut pines). 
The conversion of a conifer dominated peri-urban forest to a broadleaf dominated forest and finally to a forest of broadleaf trees have to be implemented through a series of cutting and thinning treatments, which gradually will redistribute the growing space. The specific characteristics of the treatments, the time period between treatments, and their intensity will be assigned according to the conditions that exist each time.

In areas where the density of broadleaf trees is low and the density of pine overstory is high, the transition to the broadleaf species' dominance will delay, while in areas with a high density of broadleaf trees and a sparse pine overstory the transition will be immediate.

A significant issue that must be decisive in the selection of appropriate silvicultural treatments that are going to be applied in each case, is the protection of forest soil against erosion. In this context, especially in areas with a high inclination, the vegetation density and ground coverage maintained by the tree crown projections have to be high, if possible.

The next step in the areas of broadleaf forest, or in the areas where the broadleaf trees will dominate, is to design the future silvicultural treatment approach. This approach has to incorporate services such soil protection and forest recreation.

In areas with a low inclination, silvicultural treatments must have as objective to create formations where the density of broadleaf trees in some cases will be low, and trees with large dimensions and crowns have to be grown. In general, in recreational forests the tree spacings must vary [1].

On the other hand, in areas with high inclination, the creation of dense formations of broadleaf trees for the protection of soils must be the objective. In cases of low productivity areas (worst sites) with high inclination, it is preferable a dense stratum of shrub form broadleaf trees with a very sparse overstory of conifer trees (if applicable).

\section{Application of the Two Different Silvicultural Appro- aches in the Peri-Urban Forest of Xanthi}

Each type of silvicultural treatments was applied in three replicates of about 1.5 ha in the peri - urban forest of Xanthi (Figure 4). In each replicate, two fixed area circular plots having a radius of $13 \mathrm{~m}$ (area of $531 \mathrm{~m}^{2}$ ) were randomly established in 2016. In each plot the breast height diameter and total height of all trees (dead and living) of the plot having a breast height diameter of $3 \mathrm{~cm}$ and above were measured and registered. The most broadleaved trees were in the understory. Very few of the tallest broadleaved trees had an analogous height to their adjacent pine trees that in most cases were intermediate or codominant trees. In the present study (and analyses), the pines are considered to grow in the overstory and the broadleaf trees are considered to belong to lower stories. Moreover, in each plot, each measured living tree was classified according to its crown class to dominant, codominant, intermediate or suppressed following the classification of $\operatorname{Kraft}[15,16]$. This classification was made separately in regard to the pine trees and for the broadleaved trees. In the understory, apart from the broadleaf trees, in a plot of traditional treatments there is a small Juniperus oxycedrus L. tree. In the following analyses (crown class classification, basal area calculation, etc.) this tree was included in the broadleaved component of the plots.

In September of 2016, overstory pine cuttings and thinning of the broadleaf trees in the lower stories took

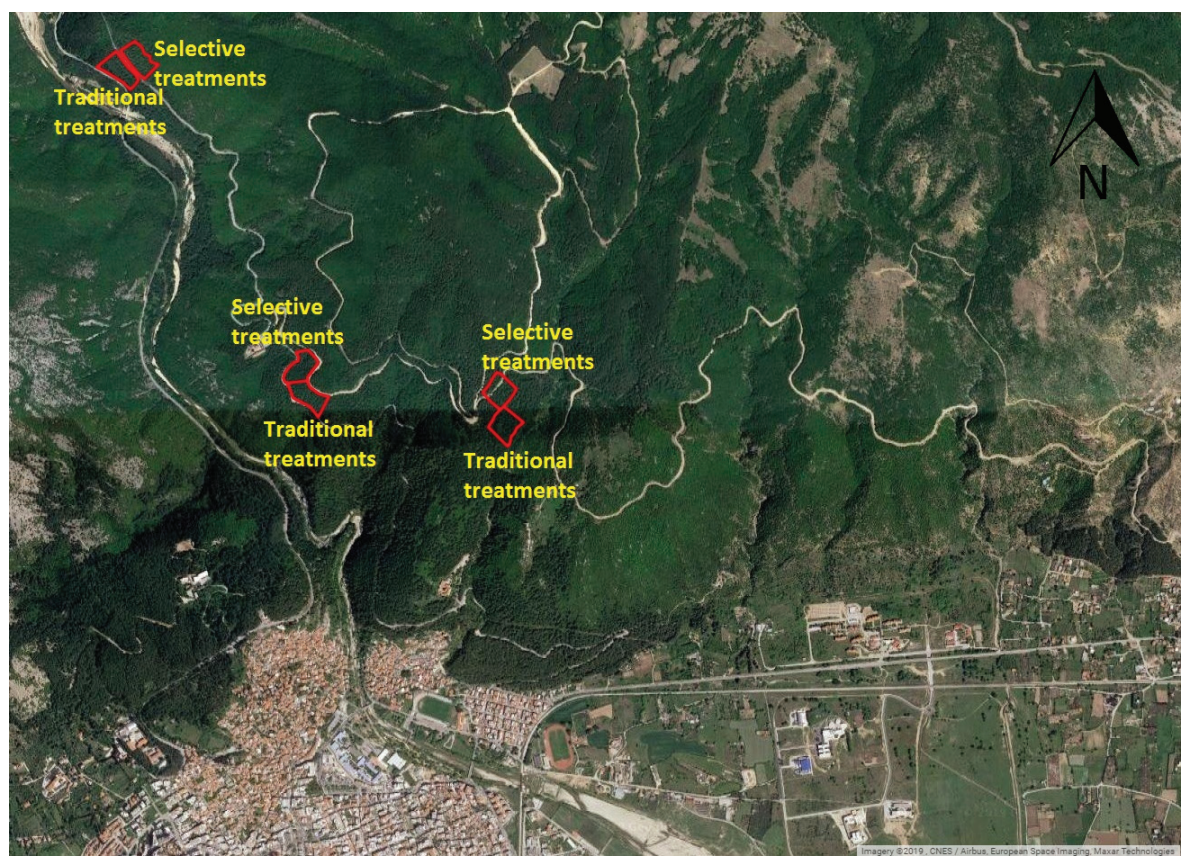

FIGURE 4. The three replicates where the traditional and the selective treatments were applied (source: Imagery @2019, CNES / Airbus, European Space Imaging, Maxar Technologies). 
place in the three replicates of each of the two types of silvicultural treatments. In each plot the characteristics of cut trees were recorded.

In the results section basal area data of all trees (dead and living) and crown class data of living trees are analyzed. This happened since the aim of result analysis was to highlight the different approaches of the two types of treatments as these are reflected in the amount of the removed basal area of both dead and living trees and in the crown class of cut living trees. The crown class distribution of trees provides information that contributes to a better management of forest stands [20]. Moreover, since both types of treatments aim at the removal of dead trees, the incorporation of dead trees in the basal area analysis provides a better insight into the intensity of each silvicultural approach. However, before the cuttings and thinning, only 9 dead trees (five pines and four broadleaf trees) were found in the plots where the two different types of treatments were applied.

In the plots where the traditional and the selective treatments were applied, the ratio (proportion) of cut pines or broadleaf trees belonging in a crown class is calculated when the number of cut trees of the specific crown class is divided by the total number of cut trees. In the comparisons between ratios, the $Z$ test was used [21], while in the comparisons between basal areas the t test was used.

\section{RESULTS}

In the following section, the basal area data are referred to both dead and living trees.

In the six plots of traditional treatments the total basal area, from $12.41 \mathrm{~m}^{2}\left(38.96 \mathrm{~m}^{2} \cdot \mathrm{ha}^{-1}\right)$, before the cuttings (and thinning) became $9.85 \mathrm{~m}^{2}\left(30.93 \mathrm{~m}^{2} \cdot \mathrm{ha}^{-1}\right)$ after the cuttings (and thinning). The basal area of pine overstory of $11.96 \mathrm{~m}^{2}$ (37.54 $\left.\mathrm{m}^{2} \cdot \mathrm{ha}^{-1}\right)$ became $9.44 \mathrm{~m}^{2}\left(29.64 \mathrm{~m}^{2} \cdot \mathrm{ha}^{-1}\right)$, exhibiting a reduction of $21.05 \%$, while the basal area of broadleaf trees of $0.45 \mathrm{~m}^{2}\left(1.42 \mathrm{~m}^{2} \cdot \mathrm{ha}^{-1}\right)$ became $0.41 \mathrm{~m}^{2}$
(1.29 $\left.\mathrm{m}^{2} \cdot \mathrm{ha}^{-1}\right)$, exhibiting a reduction of $8.93 \%$ (Figure 5). On the other hand, in the six plots of selective treatments the total basal area of $12.51 \mathrm{~m}^{2}\left(39.27 \mathrm{~m}^{2} \cdot \mathrm{ha}^{-1}\right)$, before the cuttings (and thinning) became $7.58 \mathrm{~m}^{2}\left(23.81 \mathrm{~m}^{2} \cdot \mathrm{ha}^{-1}\right)$ after the cuttings (and thinning). The basal area of pine overstory from $11.45 \mathrm{~m}^{2}$ (35.93 $\left.\mathrm{m}^{2} \cdot \mathrm{ha}^{-1}\right)$ became $6.69 \mathrm{~m}^{2}$ (20.99 $\left.\mathrm{m}^{2} \cdot \mathrm{ha}^{-1}\right)$, exhibiting a reduction of $41.57 \%$, while the basal area of broadleaf trees of $1.06 \mathrm{~m}^{2}\left(3.34 \mathrm{~m}^{2} \cdot \mathrm{ha}^{-1}\right)$ became 0.90 $\mathrm{m}^{2}\left(2.82 \mathrm{~m}^{2} \cdot \mathrm{ha}^{-1}\right)$, exhibiting a reduction of $15.77 \%$ (Figure $5)$. In the established plots, before cuttings (and thinning), total basal area was not statistically significantly different ( $p>0.05$ ) between the two types of silvicultural treatments (t-test, $t=-0.087$ and $p=0.933$ ). After cuttings (and thinning), the plots of selective treatments had statistically significantly lower $(p<0.05)$ total basal area than those of traditional treatments ( $t$-test, $t=2.611$ and $p=0.027$ ). In addition, in the plots of selective treatments, basal area of all cut trees was statistically significantly greater $(p<0.05)$ than that of the plots of traditional treatments (t-test, $t=-3.997$ and $p=0.003$ ).

In the Figures 6 and 7, the number of living trees in the different crown classes before and after the cuttings (and thinning), in the plots where traditional and selective treatments were applied, is presented. There were no differences $(p>0.05)$ in the ratios (proportions) of cut pine trees in each of the three crown classes (dominant, codominant and intermediate trees) between the two different types of silvicultural treatments, in the measured plots. There were no suppressed pine trees in the plots were the traditional treatments were applied (Table 1). In the case of broadleaf trees, the ratios (proportions) of cut trees belonging in the dominant and suppressed trees in the selective treatments were higher, compared to the corresponding ratios in the traditional treatments. In the traditional treatments the ratio (proportion) of cut intermediate trees was higher $(p<0.05)$ than that of selective treatments, while there was no difference $(p>0.05)$ in the ratios of cut codominant trees in the plots of the two different types of treatments (Table 1).

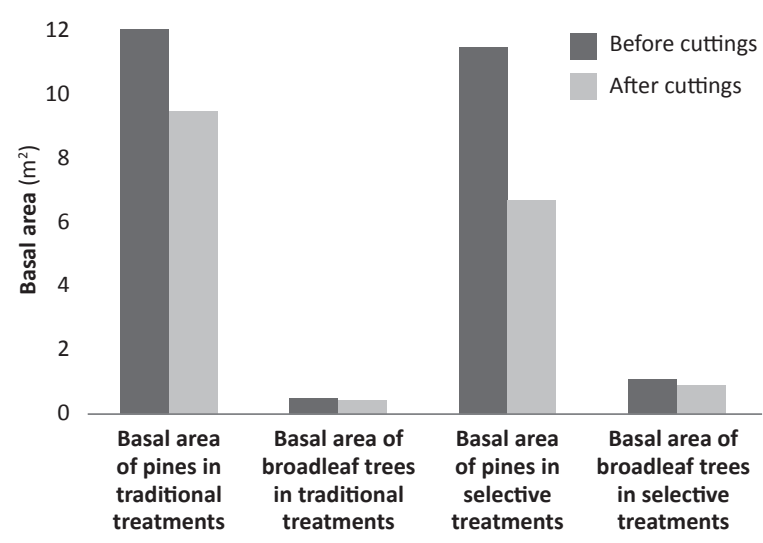

FIGURE 5. Basal area of pines and broadleaf trees before and after the cuttings (and thinning), in the plots where traditional and selective treatments were applied. 
TABLE 1. Ratios (proportions) of living pines and broadleaf trees of different crown classes that were cut (out of the total number of trees that were cut) in the plots where traditional and selective treatments were applied.

\begin{tabular}{ccc}
\hline & Ratios & Comparison of the ratios \\
\hline $\begin{array}{c}\text { Dominant pine trees that were cut in the traditional } \\
\text { treatments }\end{array}$ & $\begin{array}{c}\text { Dominant pine trees that were cut in the selective } \\
\text { treatments }\end{array}$ \\
0.49 & $0.53 \quad-0.391$
\end{tabular}

Codominant pine trees that were cut in the traditional Codominant pine trees that were cut in the selective treatments treatments

Intermediate pine trees that were cut in the traditional treatments

$$
0.37
$$

Dominant broadleaf trees that were cut in the traditional treatments

Codominant broadleaf trees that were cut in the traditional treatments

$$
0.29
$$

Intermediate broadleaf trees that were cut in the traditional treatments

$$
0.67
$$

Suppressed broadleaf trees that were cut in the traditional treatments
Intermediate pine trees that were cut in the selective treatments

$$
0.23
$$

Dominant broadleaf trees that were cut in the selective treatments

Codominant broadleaf trees that were cut in the selective treatments

0.15

Intermediate broadleaf trees that were cut in the selective treatments

$$
0.28
$$

Suppressed broadleaf trees that were cut in the selective treatments

$$
0.04
$$

0.37

$-3.051$

0.006

In the comparisons between ratios, the $\mathrm{Z}$ test was used. In the plots were the traditional and the selective treatments were applied, the ratio of cut pines or broadleaf trees belonging in a crown class is calculated when the number of cut trees of the specific crown class is divided by the total number of cut trees.

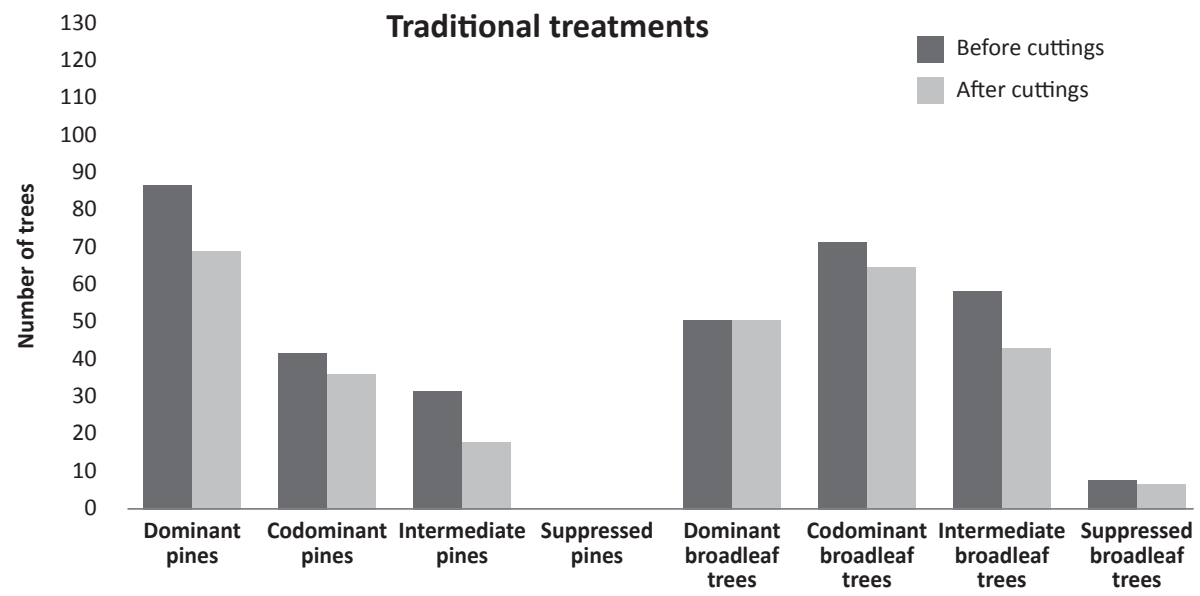

FIGURE 6. Number of pines and broadleaf trees in the different crown classes before and after the cuttings (and thinning), in the plots where the traditional treatments were applied. 


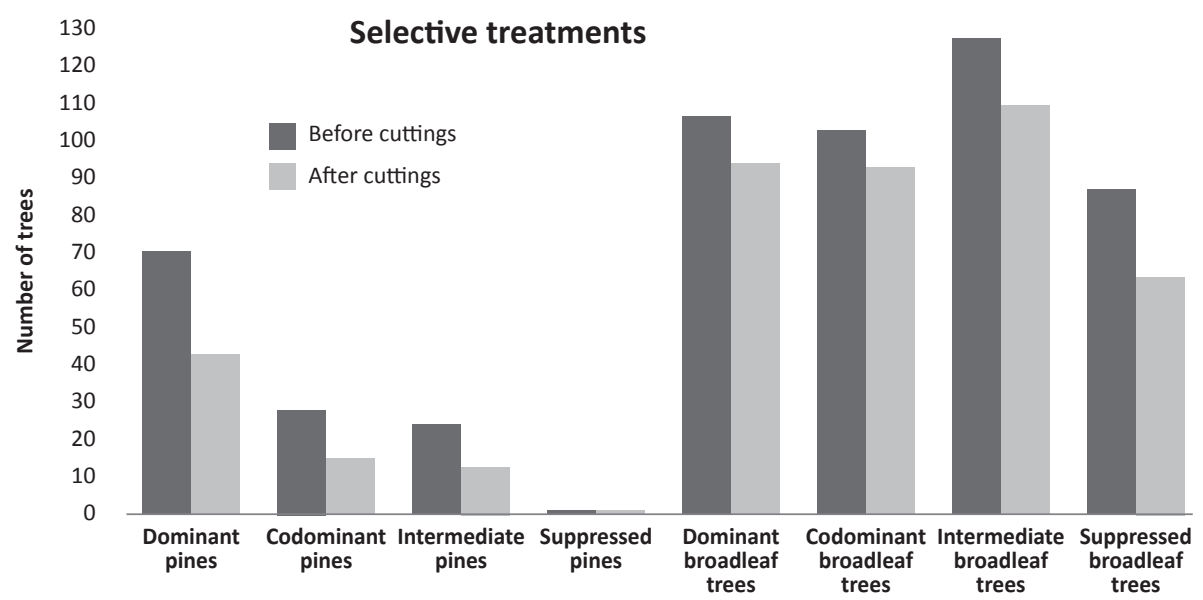

FIGURE 7. Number of pines and broadleaf trees in the different crown classes before and after the cuttings (and thinning), in the plots where the selective treatments were applied.

\section{DISCUSSION}

The intensity of treatments was higher in terms of the basal area of cut trees in the selective silvicultural approach, compared to the traditional treatments in the peri-urban forest of Xanthi. In selective treatments all cut trees had greater $(p<0.05)$ basal area compared to that of traditional treatments. Moreover, it must be mentioned that before the application of treatments there was no difference $(p>0.05)$ in the total basal area between the plots where the two different types of treatments were applied. The higher amount of basal area of cut trees in the selective treatments is related to the need for the release of the broadleaved formations from the overstory pine competition, that results in more intense overstory pine cuttings in areas with dense (or rather dense) formations of broadleaf trees. However, as mentioned in the description of the selective treatments, their overstory cutting intensity depends on the spatial distributions and densities of broadleaved and conifer trees.

Thinning can be a satisfactory method for the restoration of hardwood species under conifer plantations [22, 23]. In a Criptomeria japonica plantation of 20 years old, Seiwa et al. [24] applied thinning treatments of two intensities. In intensive thinning the $60.5 \%$ of the tree volume was cut, while in the week thinning the $28.3 \%$ of the tree volume was cut. They found that a mixed at the level of canopy conifer hardwood forest is more possible to be developed and occur more quickly after the intensive thinning, compared to the week thinning. Harmer et al. [25], after a study in a Pinus nigra-Pinus sylvestris plantation, they mentioned that in the conversion of pine plantations in a woodland of broadleaf trees, an extensive reduction of canopy may be applied. However, they referred that this treatment is the proper approach in areas where the ground flora species can have a negative effect on regeneration, while fast growing species is likely to be naturally established quickly. Mercurio and Spinelly [26] recommend the creation of gaps for the natural regeneration establishment of native species under the
Mediterranean softwood plantations. They also refer that the size of the gap depends on the species and the management goals. On the other hand, Alday et al. [27] mentioned that for the conversion of Pinus radiata plantations to native forest using natural regeneration clear cutting treatments can be used.

There were not differences $(p>0.05)$ in the ratios (proportions) of the three crown classes (dominant, codominant and intermediate) of cut pine trees between the two different types of treatments. The main difference in the overstory cuttings between the two silvicultural approaches is the release of the lower stories of broadleaf trees, aimed in the selective treatments, while in the traditional treatments the first priority is the gradual removal of the badly formed tress and damaged trees. Badly formed trees and damaged trees are not connected to a particular crown class, and they can also have great dimensions. As a result, the ratios (proportions) of the removed pine trees that belonged in dominant, codominant and intermediate crown classes were not different in the two types of treatments.

In the broadleaf trees, the different objectives of the two types of treatments resulted in thinning with different qualitative characteristics. In selective treatments, more dominant trees $(p<0.05)$ were proportionally cut (higher ratio) than in the traditional treatments. In fact, in traditional treatments no dominant trees were cut. This was predictable since, as it is referred above, in the traditional treatments, in most cases, in the thinning of broadleaf trees the robust trees were not cut, while mainly trees with lower competitive ability were removed. In this context, in the thinning of traditional treatments more intermediate trees $(p<0.05)$ were proportionally cut, compared to selective treatments. However, in the selective treatments, more suppressed trees $(p<0.05)$ were proportionally cut, compared to the traditional treatments. In this case, this was the result of the existence of groups of sprouts, in the plots where the selective treatments were applied. In the present treatments, in these groups, badly formed sprouts that were in parallel characterized as 
suppressed, since they had a curved form, were cut, leading in the high number of suppressed trees that removed in the plots where the selective treatments were applied.

A high intensity of the thinning of broadleaf trees in the selective treatments is not an inherent feature. The intensity of thinning of the broadleaf trees in the selective treatments depends on the competition imposed in the best trees, and secondarily on the density of formations of broadleaf trees.

In the proposed selective silvicultural treatments, there is a fast conversion of the peri-urban forest in a broadleaved forest (at least in the better sites) through the fast releasement of broadleaf trees, and only in the worst sites, conifers will be the dominant component of the stands. Moreover, in the thinning of the broadleaf trees in the lower stories, the best trees that are going to be favored are going to be the robust dominant having large dimensions trees, which will give strength and stability in the stand in the future. In Great Britain, it is considered that the fast conversion of conifer plantation to woodlands of native broadleaved species through clear cutting treatments under certain ecological conditions can be more preferable compared to the gradual removal of plantation trees [25, 28, 29].

Regarding the traditional silvicultural treatments, there is no acceleration of forest dynamics in the direction of broadleaf species dominance, with all the advantages of this fast conversion. Cuttings are not targeted at the release of broadleaf species and only by chance, in the case of removal of one (or two proximate) badly formed pine tree having large dimensions, there will be a release of a group of broadleaf trees (if there were such a group under the pine tree that was cut). Moreover, in the traditional treatment, the broadleaf trees are not strengthened through the favoring of their most dynamic elements. The redistribution of the growing space does not give a significant advantage in a specific category of trees.

According to Doukalianou et al. [10], both types of silvicultural treatments reduced the potential of global warming. However, they mentioned that there is an indication that the selective treatments, which were high-intensity treatments, exhibit a high potential for the mitigation of global change.
The new proposed selective silvicultural treatments can be applied in peri-urban forests having a similar stand structure and analogous ecological conditions with the periurban forest of Xanthi.

\section{CONCLUSIONS}

The research hypothesis was verified. The intensity of treatments was higher in terms of the basal area of cut trees in the selective silvicultural approach, compared to the traditional treatments in the peri-urban forest of Xanthi. However, the overstory cutting intensity of the selective treatments depends on the spatial distributions and densities of broadleaved and conifer trees.

There were not differences $(p>0.05)$ in the ratios (proportions) of the three crown classes (dominant, codominant and intermediate) of cut pine trees between the two different types of treatments. In the broadleaf trees of the lower stories, the different objectives of the two types of treatments resulted in thinning with different qualitative characteristics.

The proposed selective silvicultural treatments will accelerate the conversion of the peri-urban forests having an understory of broadleaf trees into broadleaved forests or into mixed forests of conifers and broadleaf trees and will strengthen the most dynamic elements of broadleaf trees. Thus, in the future peri-urban forests, the risk of wildfires will be reduced, there will be an increased ability of the forest ecosystem to react after disturbances, and new abilities of stand structure manipulation in the direction of usage of peri-urban forests, for recreation and soil protection, will be created.

\section{Acknowledgments}

Supported by the European FORESMIT Project (LIFE14 CCM/ IT/000905) «FOrests for environmental sustainability, REStoration and climate change MITigation».

\section{REFERENCES}

1. HATZISTATHIS A, ISPIKOUDIS I 1995 Protection of the Nature and Architecture of the Landscape. Giahoudi, Thessaloniki, Greece, $417 p$

2. BOND W, MIDGLEY JJ 2001 Ecology of sprouting in woody plants; the persistence niche. Trends Ecol Evol 16 (1): 45-51. DOI: https://doi.org/10.1016/S0169-5347(00)02033-4

3. MILIOS E, PIPINIS E, KITIKIDOU K, BATZIOU M, CHATZAKIS S, AKRITIDOU S 2014 Are sprouts the dominant form of regeneration in a lowland Quercus pubescens-Quercus frainetto remnant forest in Northeastern Greece? A regeneration analysis in the context of grazing. New Forest 45 (2): 165-177. DOI: https://dx.doi.org/10.1007/s11056-013-9399-z
4. BATZIOU M, MILIOS E, KITIKIDOU K 2017 Is diameter at the base of the root collar a key characteristic of seedling sprouts in a Quercus pubescens-Quercus frainetto grazed forest in northeastern Greece? A morphological analysis. New Forest 48 (1): 1-16. DOI: -https://doi.org/10.1007/s11056-016-9552-6

5. MILIOS E, KITIKIDOU K, ANDREADOU P 2017 Sprouting characteristics of Quercus pubescens Willd. and Quercus frainetto Ten. trees after a wildfire: to cut or not to cut the burned trees? Eur J For Res 136 (5-6): 971-979 DOI: https://doi. org/10.1007/s10342-017-1085-9

6. MILIOS E, AKRITIDOU S 2003 Sprout propagation - Biology - Ecology - Forest Practice (in Greek). In: Hellenic Forestry Society (eds) Forest Policy, Coppice Forests, Protection of Natural Environment, Proceedings of the 11th conference of Hellenic Forestry Society, Olympia, Greece, 30 September - 3 October 2003, Hellenic Forestry Society, Greece, pp 663-673 
7. MILIOS E 2010 Facilitation process and sprouting ability as silvicultural tools in the frame of climate change. In: Ljubinko Rakonjac (ed) Forest Ecosystems and Climate Changes, Proceedings of Plenary Lectures of the International Scientific Conference: Forest Ecosystems and Climate Changes, Belgrade, Serbia 9-10 March 2010, Institute of Forestry Belgrade, Serbia, pp 137-142

8. SJOLUND MJ, JUMP AS 2013 The benefits and hazards of exploiting vegetative regeneration for forest conservation management in a warming world. Forestry 86 (5): 503-513. DOI: https://doi.org/10.1093/forestry/cpt030

9. MAZZA G, ANGELLI AE, CANTIANI P, CHIAVETTA U, DOUKALIANOU F, KITIKIDOU K, MILIOS E, ORFANOUDAKIS M, RADOGLOU K, LAGOMARSINO A 2019 Short-term effects of thinning on soil $\mathrm{CO} 2, \mathrm{~N} 2 \mathrm{O}$ and $\mathrm{CH} 4$ fluxes in Mediterranean forest ecosystems. Sci Total Environ 651: 713-724. DOI: https:// doi.org/10.1016/j.scitotenv.2018.09.241

10. DOUKALIANOU F, RADOGLOU K, ANGELLI AE, KITIKIDOU K, MILIOS E, ORFANOUDAKIS M, LAGOMARSINO A 2019 Annual Greenhouse-Gas Emissions from Forest Soil of a Peri-Urban Conifer Forest in Greece under Different Thinning Intensities and Their Climate-Change Mitigation Potential. Forest Sci 65 (4): 387-400. DOI: https://doi.org/10.1093/forsci/fxy069

11. KITIKIDOU K, MILIOS E, RADOGLOU K 2017 Single-entry volume table for Pinus brutia in a planted peri-urban forest. Annals of Silvicultural Research 41 (2): 74-79. DOI: https://doi. org/10.12899/asr-1437

12. DE MEO I, ANGELLI AE, GRAZIANI A, KITIKIDOU $K$ LAGOMARSINO A, MILIOS E, RADOGLOU K, PALETTO A 2017 Deadwood volume assessment in Calabrian pine (Pinus brutia Ten.) peri-urban forests: Comparison between two sampling methods. J Sustain Forest 37 (7): 666-686. DOI: https://doi.org/ 10.1080/10549811.2017.1345685

13. PAPAIOANNOU G 2008 The torrential environment of river Kosynthos (in Greek with English summary). MSc. thesis, Democritus University of Thrace, Department of Forestry and Management of the Environment and Natural Resources, Nea Orestiada, Greece, $118 \mathrm{p}$

14. DAFIS S 1992 Applied Silviculture (in Greek). Giahoudi Giapouli, Thessaloniki, Greece, $258 \mathrm{p}$

15. OLIVER CD, LARSON BC 1996 Forest Stand Dynamics. John Wiley \& Sons, Inc. New York, USA, $520 p$

16. SMITH DM, LARSON BC, KELTY MJ, ASHTON PMS 1997 The practice of silviculture: applied forest ecology. John Wiley \& Sons, Inc. New York, USA, $537 \mathrm{p}$

17. ATHANASIADIS N 1986 Forest botany, Part ॥ (in Greek). Giahoudi - Giapouli, Thessaloniki, Greece, 309 p

18. DAFIS S 1986 Forest ecology (in Greek). Giahoudi - Giapouli, Thessaloniki, Greece, $443 p$
19. KORAKIS G 2015 Forest botany (e-book) (in Greek). Association of Greek Academic Libraries, Athens, Greece, 619 p. URL: http://hdl.handle.net/11419/742

20. BOUNTIS D, MILIOS E 2017 Does crown class classification improve the initiation and development analysis of post-fire Pinus brutia stands? CERNE 23 (1): 61-68. DOI: https://-doi.or $\mathrm{g} / 10.1590 / 01047760201723012260$

21. COX DR 2006 Principles of Statistical Inference. Cambridge University Press, New York, USA, $236 \mathrm{p}$

22. UTSUGI E, KANNO H, UENO N, TOMITA M, SAITOH T, KIMURA M, KANOU K, SEIWA K 2006 Hardwood recruitment into conifer plantations in Japan: Effects of thinning and distance from neighboring hardwood forests. Forest Ecol Manag 237 (1-3): 15-28. DOI: https://doi.org/10.1016/i.foreco.2006.09.011

23. KITAGAWA R, UENO M, MASAKI T 2018 Initial effects of thinning and concomitant disturbance on the understory woody Community in Japanese cedar plantation. J Forest Res-JPN 23 (2): 120-128. DOI: https://doi.org/10.1080/13416979.2018.14 $\underline{30653}$

24. SEIWA K, ETOH Y, HISITA M, MASAKA K, IMAJI A, UENO N, HASEGAWA Y, KONNO M, KANNO H, KIMURA M 2012 Roles of thinning intensity in hardwood recruitment and diversity in a conifer, Criptomeria japonica plantation: A 5-year demographic study. Forest Ecol Manag 269: 177-187. DOI: https://doi. org/10.1016/i.foreco.2011.12.014

25. HARMER R, KIEWITT A, MORGAN G 2012 Effects of overstorey retention on ash regeneration and bramble growth during conversion of a pine plantation to native broadleaved woodland. Eur J For Res 131 (6): 1833-1843. DOI: https://doi. org/10.1007/s10342-012-0636-3

26. MERCURIO R, SPINELLI R 2012 Exploring the silvicultural and economic viability of gap cutting in Mediterranean softwood plantations. For Stud China 14 (1): 63-69. DOI: https://doi. org/10.1007/s11632-012-0103-8

27. ALDAY JG, EXTEBERRIA E, AMETZAGA I 2017 Conversion of Pinus radiata plantations to native forest after harvest operations: a north Iberian Peninsula case study. Eur J For Res 136 (5-6): 801810. DOI: https://doi.org/10.1007/s10342-017-1071-2

28. HARMER R, MORGAN G 2009 Storm damage and the conversion of conifer plantations to native broadleaved woodland. Forest Ecol Manag 258 (5): 879-886. DOI: https://doi.org/10.1016/i. foreco.2009.03.023

29. HARMER R, MORGAN G, BEAUCHAMP K 2011 Restocking with broadleaved species during the conversion of Tsuga heterophylla plantations to native woodland using natural regeneration. Eur J For Res 136 (2): 161-171. DOI: https://doi. org/10.1007/s10342-010-0418-8 